\title{
Effect of pain control in suspected acute appendicitis on the diagnostic accuracy of surgical residents
}

KyeongWon Kang, MD*; Woo Jeong Kim, PhD*; Kyuseok Kim, $\mathrm{PhD}^{\dagger}$; You Hwan Jo, $\mathrm{PhD}^{\dagger}$; Joong Eui Rhee, $\mathrm{PhD}^{\dagger}$; Jin Hee Lee, $\mathrm{PhD}^{\dagger}$; Yu-jin Kim, $\mathrm{PhD}^{\dagger}$; JaeHuk Lee, $\mathrm{PhD}^{\dagger}$; Sung-Bum Kang, $\mathrm{PhD}^{\ddagger}$; Duck-Woo Kim, PhD ${ }^{\ddagger}$; Kyung-Ho Lee, $\mathrm{PhD}^{\S}$; Young Hoon Kim, PhD ${ }^{\S}$; Hyun Mi Park, BSc ${ }^{\dagger}$

\section{ABSTRACT}

Objective: To determine the influence of early pain relief for patients with suspected appendicitis on the diagnostic performance of surgical residents.

Methods: A prospective randomized, double-blind, placebocontrolled trial was conducted for patients with suspected appendicitis. The patients were randomized to receive placebo (normal saline intravenous [IV]) infusions over 5 minutes or the study drug (morphine $5 \mathrm{mg}$ IV). All of the clinical evaluations by surgical residents were performed 30 minutes after administration of the study drug or placebo. After obtaining the clinical probability of appendicitis, as determined by the surgical residents, abdominal computed tomography was performed. The primary objective was to compare the influence of IV morphine on the ability of surgical residents to diagnose appendicitis.

Results: A total of 213 patients with suspected appendicitis were enrolled. Of these patients, 107 patients received morphine, and 106 patients received placebo saline. The negative appendectomy percentages in each group were similar $13.8 \%$ in the placebo group and $3.2 \%$ in the pain control group, $p=0.62$ ). The perforation rates in each group were also similar $(18.9 \%$ in the placebo group and $14.3 \%$ in the pain control group, $p=0.75)$. Receiver operating characteristic analysis revealed that the overall diagnostic accuracy in each group was similar (the area under the curve of the placebo group and the pain control group was $0.63 \mathrm{v}$. 0.61 , respectively, $p=0.81$ ).

Conclusions: Early pain control in patients with suspected appendicitis does not affect the diagnostic performance of surgical residents.

\section{RÉSUMÉ}

Objectif: L'étude visait à déterminer l'incidence du soulagement précoce de la douleur chez des patients souffrant vraisemblablement d'appendicite, sur l'efficacité de la pose du diagnostic par les résidents en chirurgie.

Méthode: Un essai comparatif contre placébo, prospectif, à répartition aléatoire et à double insu a été mené chez des patients souffrant vraisemblablement d'appendicite. Ceux-ci ont reçu au hasard soit un placébo (solution physiologique salée intraveineuse [i.v.]) en 5 minutes, soit le médicament à l'étude (morphine, $5 \mathrm{mg}$, i.v.). Toutes les évaluations cliniques ont été réalisées par les résidents en chirurgie, 30 minutes après l'administration du placébo ou du médicament à l'étude. Après confirmation des probabilités cliniques d'appendicite par les résidents en chirurgie, un examen par tomodensitométrie abdominale a été effectué. L'objectif principal était de comparer l'incidence de l'administration de la morphine, par voie intraveineuse, sur la capacité des résidents en chirurgie à poser le diagnostic d'appendicite.

Résultats: Au total, 213 patients souffrant vraisemblablement d'appendicite ont participé à l'étude. Sur ce nombre, 107 ont reçu de la morphine, et 106, la solution salée placébo. Le pourcentage d'appendicectomie négative était comparable dans chaque groupe $(3.8 \%$ dans le groupe placébo et $3.2 \%$ dans le groupe de soulagement de la douleur; $p=0.62$ ). Le taux de perforation était également comparable dans chacun des groupes (18.9\% dans le groupe placébo et $14.3 \%$ dans le groupe de soulagement de la douleur; $p=0.75$ ). L'analyse caractéristique de la performance d'un test a révélé que, dans I'ensemble, I'exactitude diagnostique était comparable dans chaque groupe (la surface sous la courbe dans le groupe placébo et celle dans le groupe de soulagement de la douleur étaient de 0.63 et de 0.61 , respectivement; $p=0.81$ ). Conclusion: Le soulagement précoce de la douleur chez les patients souffrant vraisemblablement d'appendicite n'a pas d'incidence sur la pose du diagnostic par les résidents en chirurgie.

Keywords: acute appendicitis, emergency department, morphine

From the *Emergency Medicine Department, Jeju National University Hospital, Jeju-si, Republic of Korea, tEmergency Department, $\neq D e p a r t m e n t ~ o f$ Surgery, and §Department of Radiology, Seoul National University Bundang Hospital, Sungnam-si, Republic of Korea.

Correspondence to: Dr. Woo Jeong Kim, Emergency Medicine Department, Jeju National University Hospital, Aran 13gil Jeju-si, Republic of Korea; kkwpps@hanmail.net.

This article has been peer reviewed.

(C) Canadian Association of Emergency Physicians 
Acute appendicitis is one of the most common conditions requiring surgery in emergency department (ED) patients. ${ }^{1}$ Diagnosis is made from the physical examination, the patient history, and diagnostic imaging. Pain relief was traditionally delayed for fear that it may affect the physical examination and prevent an accurate diagnosis. The administration of analgesics for patients with unspecified abdominal pain has been an area of disagreement between surgeons and emergency physicians in the past. ${ }^{2}$ More recently, studies have demonstrated the safety of analgesics for abdominal pain, showing that early pain control reduces the stress response and may even improve the physical examination. ${ }^{3-7}$ However, there were limitations to those studies, including a small sample size, ${ }^{4,5,7}$ a lack of double-blinded methods, ${ }^{6}$ and diagnoses that were conducted primarily by emergency physicians. ${ }^{3,4}$ To overcome these limitations, a larger double-blind study comparing the diagnostic performance of surgery residents was conducted herein to evaluate the effect of pain control in patients with suspected appendicitis.

\section{METHODS}

\section{Study design and setting}

We conducted a prospective, randomized, doubleblind, placebo-controlled trial for patients with suspected acute appendicitis from October 2007 to May 2009 at an urban, tertiary care emergency department (ED) with an annual admittance of 65,000 patients. The Institutional Review Board of our hospital approved this study, and all participants gave valid informed consent.

\section{Study subjects}

This study enrolled patients who visited the ED with suspected acute appendicitis. ${ }^{8}$ All nonpregnant patients $>15$ years old who presented with nontraumatic right lower quadrant pain of less than 48 hours' duration were eligible for the study. Patients who were transferred from other hospitals with a diagnosis of appendicitis or were given analgesics for abdominal pain were excluded. Patients with renal insufficiency or allergy to computed tomography (CT) contrast dye were excluded from the study.

\section{Study protocol and data acquisition}

All patients were initially examined by an emergency physician, which included emergency residents and specialists in emergency medicine (Figure 1), and if the patient appeared to be eligible, the research nurse (H.M.P.) was notified. The research nurse confirmed the study criteria and obtained informed consent. After consent was obtained, the research nurse used a visual analogue scale (VAS) to determine the patient's subjective level of pain. Then the patients were randomized to receive placebo (normal saline intravenous [IV]) or study drug (morphine $5 \mathrm{mg}$ IV). Randomization was performed by the treating nurse using a random number generator in a 1:1 ratio using permuted random block sizes of 4, 6, and 8. Sequentially numbered, opaque, and sealed envelopes were prepared by the research nurse and used by the treating nurse. All personnel (emergency physicians, surgical residents, and research nurses) involved in the study were blinded to the assignment. Thirty minutes after the administration of analgesics, the patient's VAS score was measured by the research nurse.

First- to fourth-year surgical residents participated in this study. All of the clinical evaluations were performed by surgical residents 30 minutes after the administration of the placebo or the study drug. The surgical residents were asked to predict the probability that the patients had acute appendicitis by choosing one of four groups corresponding to clinical probabilities of 80 to $100 \%, 60$ to $79 \%, 40$ to $59 \%$, and 20 to $39 \% .{ }^{9,10}$

After obtaining the clinical probability of acute appendicitis, abdominal CT scans (Brilliance, Phillips Medical Systems, Cleveland, $\mathrm{OH}$ ) were performed. Contrast material (Ultravist 370, Schering, Berlin, Germany) was infused at a dose of $2 \mathrm{~mL} / \mathrm{kg}$. The disposition (discharge or operation and admission) of the patient was determined by a surgical resident after considering the physical examination, patient history, laboratory tests, and CT results. Standardized data collection forms were used throughout the study, including demographic information, patient symptoms and signs, and laboratory test results.

\section{Objectives}

The primary objective was to compare the diagnostic performance of surgical residents for patients who received or did not receive analgesics. The final diagnosis of acute appendicitis was based on pathology 


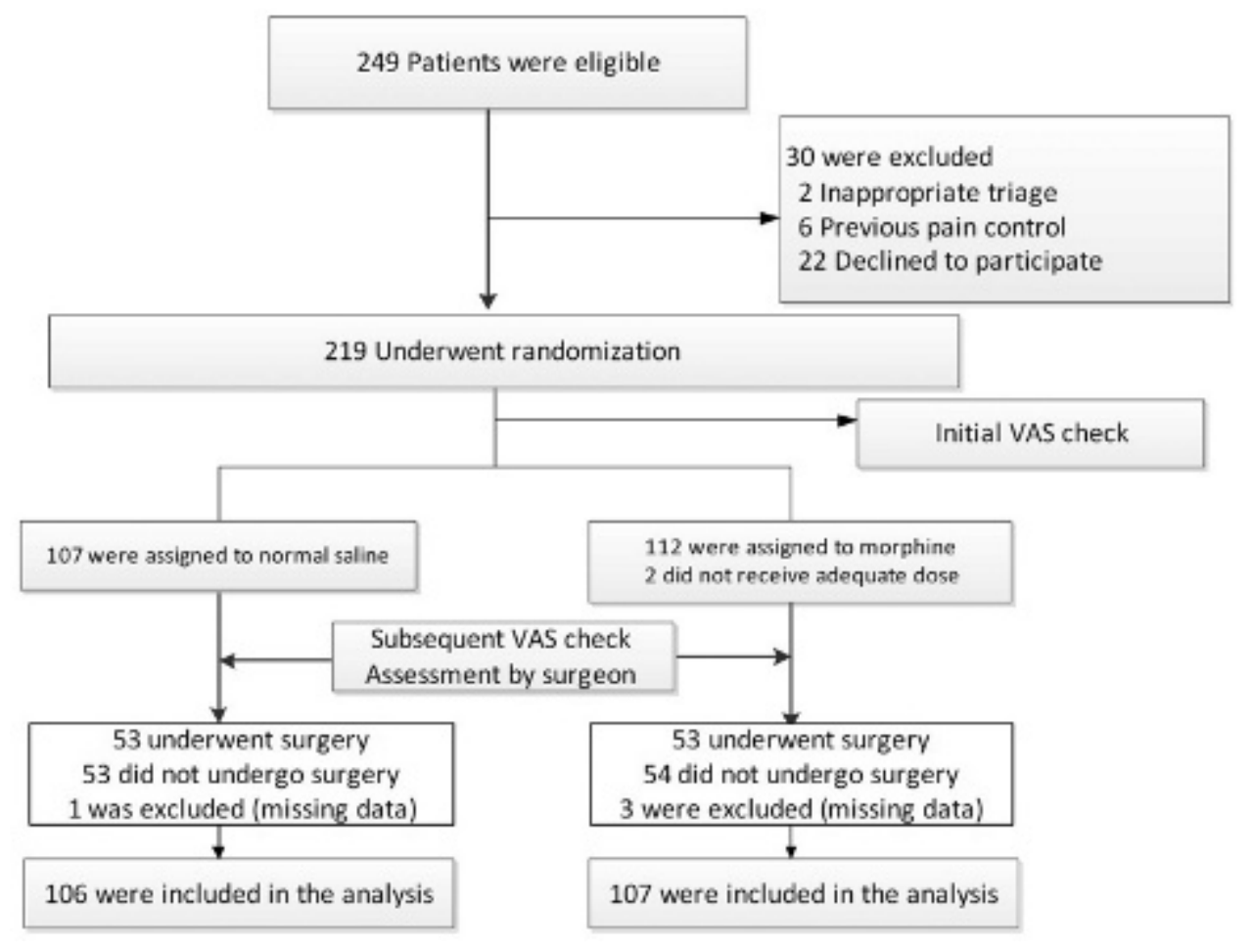

Figure 1. Study scheme. VAS = visual analogue scale.

after the operation. In cases where no operation was performed, a clinical follow-up or a telephone interview was conducted after 3 months. The secondary objectives included a negative appendectomy rate, a perforation rate, and the VAS score before and after medication.

\section{Data analysis}

For the sample size calculation, we used data from our previous study regarding the diagnostic performance of surgical residents. ${ }^{10}$ The area under the curve (AUC) of surgical residents was 0.66 , and we assumed that pain control could mask the diagnosis of appendicitis up to an AUC of 0.5 . To obtain $90 \%$ statistical power with a one-sided $\alpha$ equal to 0.05 , it was necessary to have 106 patients in each group. Assuming a dropout rate of $10 \%, 117$ patients per group were required. Paired $t$-tests were used to compute differences in VAS scores between the two groups. We performed receiver operating characteristic (ROC) curve analysis to compare the diagnostic accuracy of the surgical residents. The AUC was calculated and compared.

Statistical analyses were conducted using STATA software version 10.0 (StataCorp, College Station, TX).

\section{$\underline{\text { RESULTS }}$}

A total of 249 patients with abdominal pain suggestive of appendicitis were enrolled. Of these patients, 36 patients were excluded. The reasons for exclusion were 1) patient refusal to participate in the study $(n=22) ; 2)$ previous medication for pain control $(n=6)$; 3$)$ insufficient dose of medication $(n=2)$; 4$)$ inappropriate triage $(n=2)$; and $5)$ missing data $(n=4)$. A total of 107 patients received analgesics, and 106 patients did not receive analgesics (Figure 2).

A total of 213 patients were included in the final study. The mean age was $37.3 \pm 0.1$ years; 105 patients (46.9\%) were male, and 118 patients $(53.1 \%)$ were female. The most common additional symptoms were nausea (43\%), anorexia (38\%), and vomiting (19\%) (Table 1). In the pain control group, there was a significant difference in VAS scores 30 minutes after the administration of morphine, but there was no change in VAS scores in the no pain control group 30 minutes after the administration of saline (Table 2). A total of 116 patients received an appendectomy; 4 of these patients did not have acute appendicitis. The overall negative appendectomy rate was $3.4 \%$, and the appendiceal perforation rate was $16.4 \%$ (Table 3). The test characteristics of the surgical residents' diagnoses 


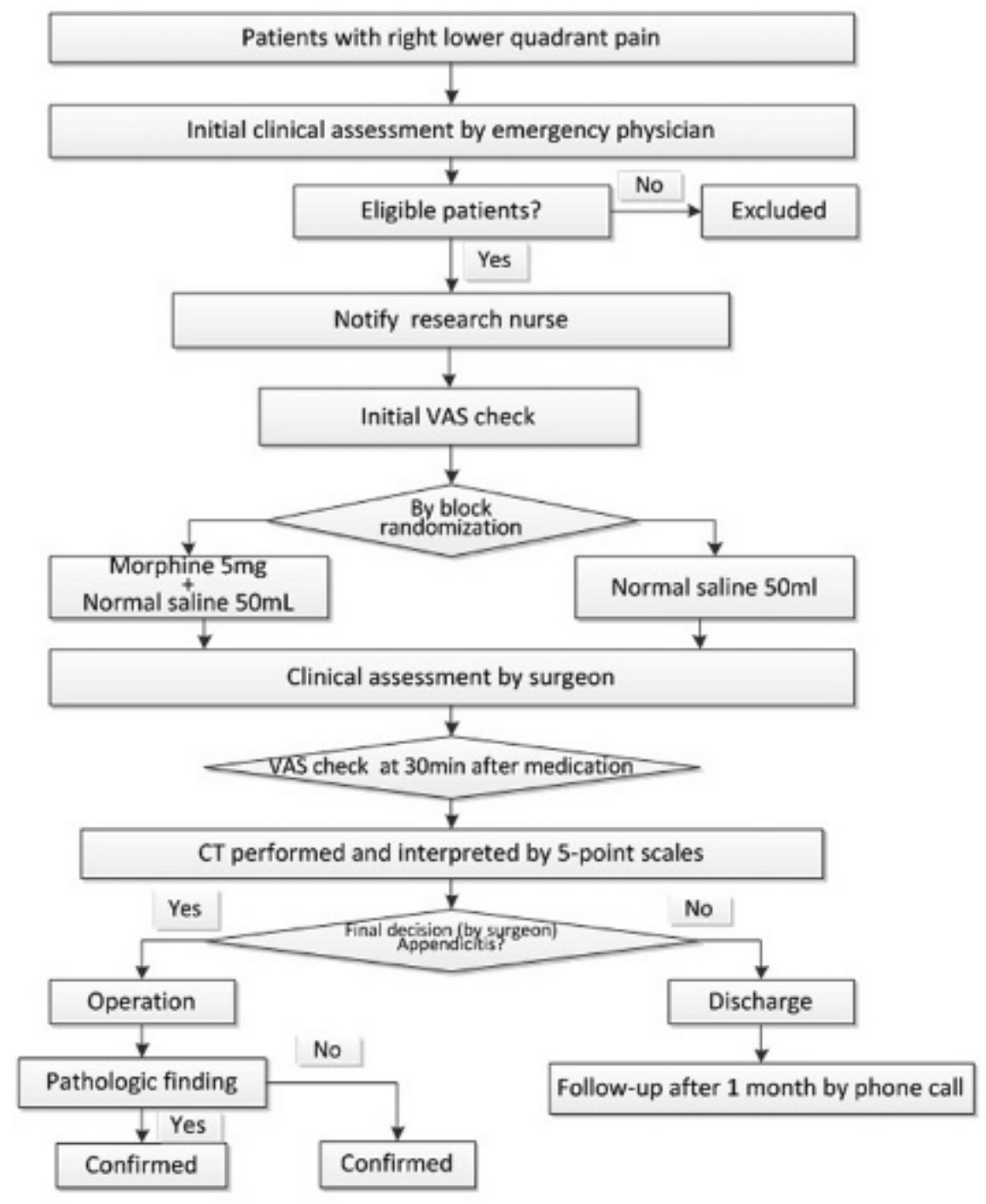

Figure 2. Study flow diagram. $\mathrm{CT}=$ computed tomography; VAS $=$ visual analogue scale.

are shown in Table 4. The clinical probabilities of acute appendicitis predicted by the surgical residents for patients receiving morphine or the placebo are presented in Figure 3. There was no significant difference in the probabilities of acute appendicitis predicted by surgical residents for patients who received morphine compared to those who did not. The ROC analysis revealed that the overall diagnostic accuracy in each category did not differ between the morphine group and the placebo group $(p=0.81)$ (Figure 4).

\section{DISCUSSION}

In this prospective, randomized, controlled study, the diagnostic performance of surgical residents for acute appendicitis in patients with abdominal pain suggestive of appendicitis did not differ significantly between the morphine group and the placebo group. To the best of our knowledge, this is the first report to compare surgical resident diagnostic performance between patients with suspected appendicitis receiving morphine versus placebo.

Acute abdominal pain is one of the most common presenting symptoms in the ED. ${ }^{11,12}$ Historically, it was recommended that no analgesics be administered for fear of obscuring the diagnosis.,13,14 Recent studies investigating early analgesic administration for abdominal pain have suggested that this practice does not reduce diagnostic accuracy. These studies have some limitations, such as limited or obscured involvement of surgeons, follow-up performed by on-study physicians, inadequate pain control, and a small sample size. ${ }^{15}$ Based on these studies, some have concluded that analgesia prior to diagnosis and disposition should be given only after the consent of the surgeon., ${ }^{2,16,17}$ 


\begin{tabular}{|c|c|c|}
\hline & No pain control (106) & Pain control (107) \\
\hline Age & $36.4 \pm 1.4$ & $38.2 \pm 1.4$ \\
\hline \multicolumn{3}{|l|}{ Sex, $n(\%)$} \\
\hline Male & $44(41.5)$ & $56(52.3)$ \\
\hline Female & $62(58.5)$ & $51(47.7)$ \\
\hline \multicolumn{3}{|l|}{ Symptoms and signs, $n(\%)$} \\
\hline Anorexia & $43(40.6)$ & $39(36.4)$ \\
\hline Nausea & $46(43.4)$ & $46(43.0)$ \\
\hline Vomiting & $23(21.7)$ & $18(16.8)$ \\
\hline Temperature & $36.8 \pm 0.7$ & $36.8 \pm 0.6$ \\
\hline Temperature $>37.3^{\circ} \mathrm{C}\left(9.1^{\circ} \mathrm{F}\right)$ & $38.3 \pm 0.8$ & $37.8 \pm 0.5$ \\
\hline Temperature $>38.0^{\circ} \mathrm{C}\left(100.4^{\circ} \mathrm{F}\right)$ & $38.8 \pm 0.6$ & $39.0 \pm 1.3$ \\
\hline White blood cell count $(\mu \mathrm{L})$ & $11632.9 \pm 4348.4$ & $11008.9 \pm 4433.3$ \\
\hline White blood cell count $>10,000 / \mu \mathrm{L}$ & $14337.0 \pm 3270.3$ & $13692.66 \pm 3559.2$ \\
\hline Segmented neutrophils (\%) & $74.2 \pm 10.6$ & $75.2 \pm 12.9$ \\
\hline Segmented neutrophils > 75\% & $82.5 \pm 5.0$ & $82.9 \pm 4.6$ \\
\hline C-reactive protein (CRP) & $4.21 \pm 5.3$ & $4.8 \pm 5.7$ \\
\hline Hospitalization period (d) & $3.98 \pm 2.1$ & $4.02 \pm 2.7$ \\
\hline
\end{tabular}

Moreover, some recent surveys have revealed that surgeons remain reluctant to provide early analgesia without a definitive diagnosis. ${ }^{18}$

Previous studies enrolled all patients with acute abdominal pain, which caused some debate about the recommended sample size of future studies. In one study, only $7 \%$ of patients with acute abdominal pain were ultimately diagnosed with a condition that, if missed, might result in increased mortality or morbidity. ${ }^{19}$ Due to this low incidence, the investigators recommended that at least 1,500 patients be included to obtain significant differences in adverse outcomes between pain control and no pain control groups. To date, no study has included such large numbers of

\begin{tabular}{|c|c|c|c|}
\hline & Placebo & Morphine & $p$ \\
\hline Initial VAS & $6.75 \pm 2.14$ & $6.50 \pm 1.09$ & \\
\hline After 30 min VAS & $6.50 \pm 2.47(p=0.19)$ & $4.38 \pm 2.56(p=0.02)$ & \\
\hline \multicolumn{4}{|l|}{ SR assessment } \\
\hline$n(\%)$ & Total $=106$ & Total $=107$ & 0.76 \\
\hline 80-100 & $25(23.6)$ & $28(26.2)$ & \\
\hline $60-79$ & 38 (35.9) & $39(36.5)$ & \\
\hline $40-59$ & $28(26.4)$ & $22(20.6)$ & \\
\hline 20-39 & 15(14.2) & $18(16.8)$ & \\
\hline \multicolumn{4}{|l|}{ CT results } \\
\hline$n(\%)$ & Total $=103$ & Total $=105$ & 0.45 \\
\hline Definitely not & $53(51.5)$ & $50(47.6)$ & \\
\hline Probably not & $3(2.9)$ & $2(1.9)$ & \\
\hline Indeterminate & $3(2.9)$ & $0(0.0)$ & \\
\hline Probably & $6(5.8)$ & $5(4.8)$ & \\
\hline Definitely & 38 (36.9) & $48(45.7)$ & \\
\hline
\end{tabular}




\begin{tabular}{|c|c|c|c|c|}
\hline Results & No pain control, $n(\%)$ & Pain control, $n(\%)$ & Total, $n(\%)$ & $p$ value \\
\hline Operation & 53 & 63 & 116 & 0.10 \\
\hline No appendicitis & $2(3.8)$ & $2(3.2)$ & $4(3.4)$ & 0.62 \\
\hline Perforated appendicitis & 10 (18.9) & $9(14.3)$ & 19 (16.4) & 0.75 \\
\hline
\end{tabular}

\begin{tabular}{|lcc|}
\hline Table 4. Diagnostic sensitivity, specificity, and likelihood ratio (diagnostic performance level set to 3, 95\% Cl) \\
\hline & Pain control, \% (95\% Cl) No pain control, \% (95\% Cl) \\
\hline Sensitivity & $73.0(60.1-83.1)$ & $67.9(53.6-79.7)$ \\
Specificity & $52.3(36.9-67.3)$ & $49.1(41.0-66.4)$ \\
Positive likelihood ratio & $1.53(1.08-2.16)$ & $1.33(1.07-2.04)$ \\
Negative likelihood ratio & $0.52(0.31-0.85)$ & $0.65(0.38-0.94)$
\end{tabular}

patients; in actuality, the total number of patients in all published articles is below this level. In the present study, we focused on patients with suspected appendicitis to determine the difference in diagnostic performance of surgical residents in the presence or absence of pain control in patients. This design is more appropriate to ascertain the impact of pain control for abdominal pain from suspected appendicitis. In patients presenting to the ED with abdominal pain, the priority is to determine the need for surgery, and appendicitis is the most common disease requiring surgery that presents in the ED. ${ }^{20}$ Furthermore, the diagnosis of appendicitis is evident by pathology or clinical follow-up. The diagnosis for patients with general abdominal pain is occasionally obscure; and in one study of pain control, the main diagnosis was abdominal pain itself. ${ }^{\text {? }}$

Previously, we studied the diagnostic performance of surgical residents' clinical impressions. ${ }^{9}$ In this study, the AUC of the surgical residents' clinical impressions was the same as in our previous data, supporting minimal bias. Previous studies of children have attempted to determine whether pain control impeded the diagnosis of appendicitis, but these studies relied on the surgeon's own confidence in diagnosis and did not use a real diagnostic standard. ${ }^{4,21}$
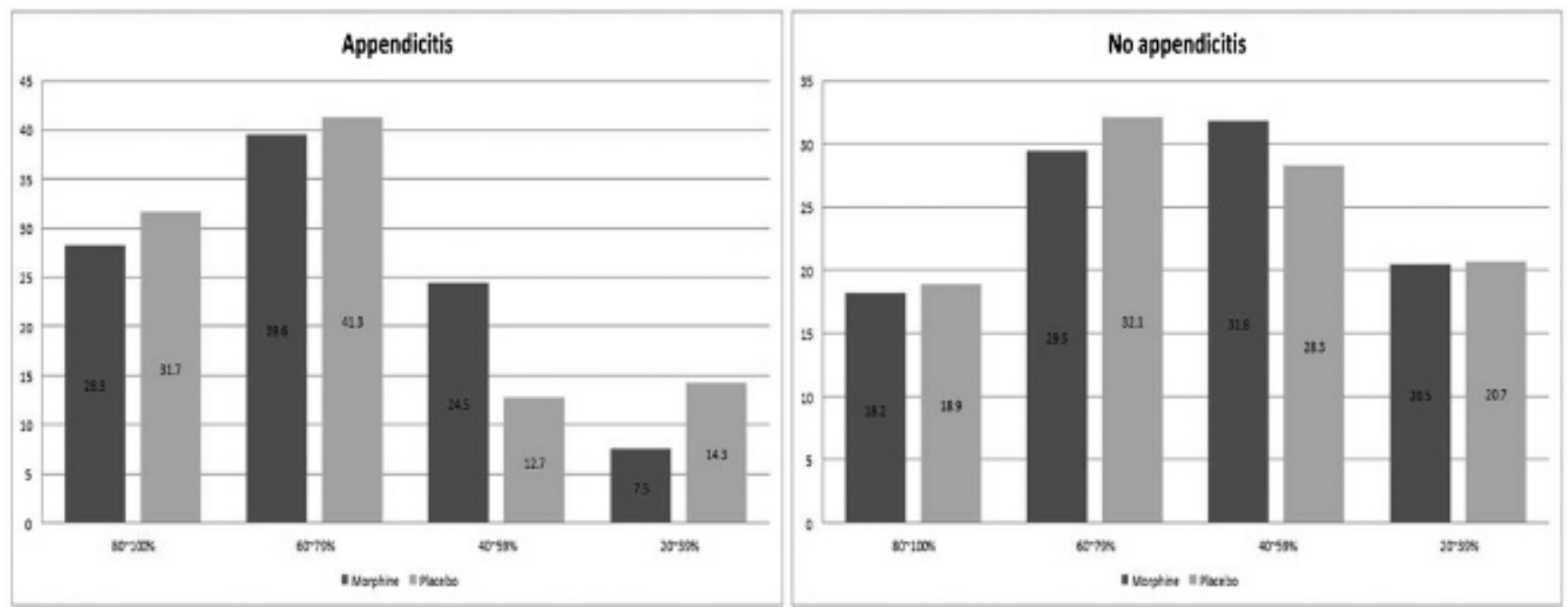

Figure 3. Clinical probability of appendicitis determined by surgical residents in both patient groups. 


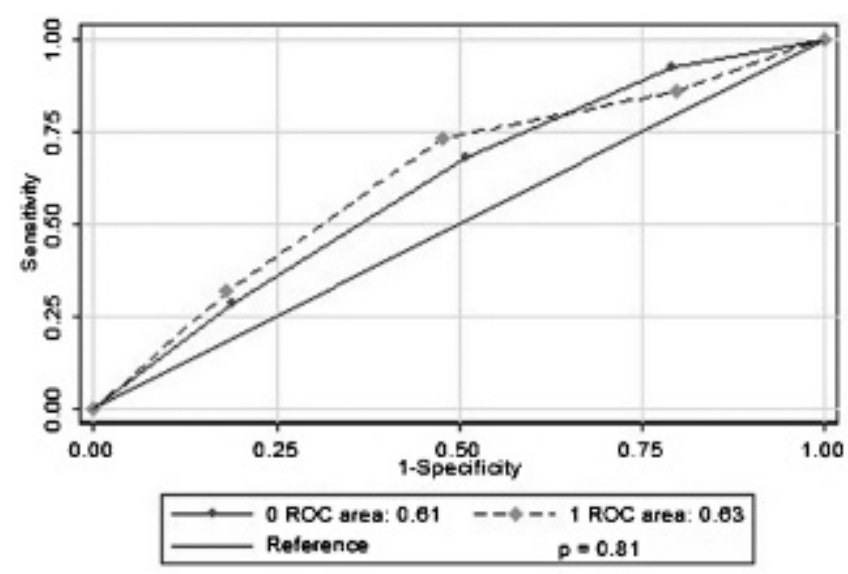

Figure 4. Compared receiver operating characteristic (ROC) curves of clinical probability. The area under the curve of the no pain control group and the pain control group is $0.61(95 \% \mathrm{Cl}$ $0.50-0.71)$ and $0.63(95 \% \mathrm{Cl} 0.52-0.73)$, respectively, $p=0.81$.

We obtained an opinion from the surgical service only after pain control. Some studies investigated changes in physical examination or clinical impression before and after pain control as a primary objective, but this design may cause some informational bias.

Theoretically, and as suggested by some studies, pain control may alter the findings of physical examinations and may have an effect on the patient's disposition, especially when patients are given high amounts of analgesics. ${ }^{3,6,18,22}$ However, this study showed that the overall clinical impression was similar with or without pain control. The administration of analgesics did not appear to affect the patient's disposition. Moreover, standard practice for abdominal pain in the ED is changing, and CT scans are increasingly used in the diagnosis of abdominal pain in the ED. ${ }^{23} \mathrm{~A}$ recent study reported that performing CT altered the leading diagnosis in approximately $50 \%$ of cases. ${ }^{24}$ In this randomized controlled trial, the administration of pain medication did not significantly reduce the diagnostic performance of surgical trainees for suspected appendicitis.

In this study, the appendiceal perforation rates and negative appendectomy rates were comparable in both groups, indicating that both the sensitivity and the specificity of the entire diagnostic process were independent of the morphine administration.

\section{LIMITATIONS}

This study has several limitations. First, this study was conducted at one institution and may not be generalized to other institutions. Second, the surgical clinical opinion in this study was provided by surgical residents, and the results may differ when boardcertified surgeons are used. Third, the administration of pain control was not based on the patient's weight; however, the distribution of weight was comparable between the two groups.

\section{CONCLUSION}

The diagnostic performance of surgical residents in predicting suspected appendicitis did not differ significantly between patients given IV morphine analgesia and those given placebo. Our results support the practice of early pain control with morphine in ED patients suspected of having acute appendicitis.

Competing interests: None declared.

\section{REFERENCES}

1. Brown JJ. Acute appendicitis: the radiologist's role. Radiology 1991;180:13-4.

2. Nissman SA, Kaplan IJ, Mann BD. Critically reappraising the literature-driven practice of analgesia administration for acute abdominal pain in the emergency room prior to surgical evaluation. Am 7 Surg 2003;185:291-6, doi:10.1016/ S0002-9610(02)01412-5.

3. Pace $S$, Burke TF. Intravenous morphine for early pain relief in patients with acute abdominal pain. Acad Emerg Med 1996; 3:1086-92, doi:10.1111/j.1553-2712.1996.tb03365.x.

4. Kim MK, Strait RT, Sato TT, et al. A randomized clinical trial of analgesia in children with acute abdominal pain. Acad Emerg Med 2002;9:281-7, doi:10.1111/j.1553-2712.2002. tb01319.x.

5. Mahadevan M, Graff L. Prospective randomized study of analgesic use for ED patients with right lower quadrant abdominal pain. Am 7 Emerg Med 2000;18:753-6, doi:10. 1053/ajem.2000.16315.

6. Thomas SH, Silen W, Cheema F, et al. Effects of morphine analgesia on diagnostic accuracy in emergency department patients with abdominal pain: a prospective, randomized trial. 7 Am Coll Surg 2003;196:18-31, doi:10.1016/S10727515(02)01480-1.

7. Wolfe JM, Smithline HA, Phipen S, et al. Does morphine change the physical examination in patients with acute appendicitis? Am 7 Emerg Med 2004;22:280-5, doi:10.1016/ j.ajem.2004.02.015.

8. Kim K, Rhee JE, Lee CC, et al. Impact of helical computed tomography in clinically evident appendicitis. Emerg Med 7 2008;25:477-81, doi:10.1136/emj.2006.044552.

9. Jo YH, Kim K, Rhee JE, et al. The accuracy of emergency medicine and surgical residents in the diagnosis of acute appendicitis. Am J Emerg Med 2010;28:766-70, doi:10.1016/ j.ajem.2009.03.017.

10. Rao PM, Rhea JT, Novelline RA, et al. Effect of computed tomography of the appendix on treatment of patients and use 
of hospital resources. N Engl 7 Med 1998;338:141-6, doi:10.1056/NEJM199801153380301.

11. Ciccone A, Allegra JR, Cochrane DG, et al. Age-related differences in diagnoses within the elderly population. Am 7 Emerg Med 1998;16:43-8, doi:10.1016/S0735-6757 (98)90063-8.

12. McCaig LF, Burt CW. National Hospital Ambulatory Medical Care Survey: 2001 emergency department summary. Adv Data 2003 Jun 4;335:1-29.

13. Zoltie N, Cust MP. Analgesia in the acute abdomen. Ann $R$ Coll Surg Engl 1986;68:209-10.

14. Tait IS, Ionescu MV, Cuschieri A. Do patients with acute abdominal pain wait unduly long for analgesia? $\mathcal{F} R$ Coll Surg Edinb 1999;44:181-4.

15. Manterola C, Astudillo P, Losada H, et al. Analgesia in patients with acute abdominal pain. Cochrane Database Syst Rev 2007;(3):CD005660.

16. Vane DW. Efficacy and concerns regarding early analgesia in children with acute abdominal pain. Pediatrics 2005;116: 1018, doi:10.1542/peds.2005-1430.

17. Armstrong FD. Analgesia for children with acute abdominal pain: a cautious move to improved pain management. Pediatrics 2005;116:1018-9, doi:10.1542/peds.2005-1719.

18. Vermeulen B, Morabia A, Unger PF, et al. Acute appendicitis: influence of early pain relief on the accuracy of clinical and US findings in the decision to operate-a randomized trial. Radiology 1999;210:639-43, doi:10.1148/ radiology.210.3.r99fe54639.

19. Flum DR, Morris A, Koepsell T, et al. Has misdiagnosis of appendicitis decreased over time? A population-based analysis. $7 A M A$ 2001;286:1748-53, doi:10.1001/jama.286. $\underline{14.1748}$.

20. Pickhardt PJ, Lawrence EM, Pooler BD, et al. Diagnostic performance of multidetector computed tomography for suspected acute appendicitis. Ann Intern Med 2011;154:78996, W-291, doi:10.7326/0003-4819-154-12-20110621000006.

21. Green R, Bulloch B, Kabani A, et al. Early analgesia for children with acute abdominal pain. Pediatrics 2005;116:97883, doi:10.1542/peds.2005-0273.

22. Attard AR, Corlett MJ, Kidner NJ, et al. Safety of early pain relief for acute abdominal pain. BMF 1992;305:554-6, doi:10.1136/bmj.305.6853.554.

23. Paulson EK, Kalady MF, Pappas TN. Clinical practice. Suspected appendicitis. N Engl 7 Med 2003;348:236-42, doi:10.1056/NEJMcp013351.

24. Abujudeh HH, Kaewlai R, McMahon PM, et al. Abdominopelvic CT increases diagnostic certainty and guides management decisions: a prospective investigation of 584 patients in a large academic medical center. $A 7 R A m \mathcal{F}$ Roentgenol 2011;196:238-43, doi:10.2214/AJR.10.4467. 